Short communication

\title{
Standardizing output-based surveillance to control non-regulated cattle diseases: Aspiring for a single general regulatory framework in the European Union
}

\author{
Lina Costa $^{\mathrm{a} * *}$, Elsa L. Duarte ${ }^{\mathrm{b}}$, Tanja Knific ${ }^{\mathrm{c}}$, Jaka Jakob Hodnik ${ }^{\mathrm{c}}$, Annika van Roon ${ }^{\mathrm{d}}$, \\ Christine Fourichon $^{\mathrm{e}}$, Xhelil Koleci ${ }^{\mathrm{f}}$, Gerdien van Schaik ${ }^{\mathrm{d}, \mathrm{i}}$, George Gunn ${ }^{\mathrm{g}}$, \\ Aurélien Madouasse ${ }^{\mathrm{e}}$, John Berezowski ${ }^{\mathrm{h}}$, Inge Santman-Berends ${ }^{\mathrm{d}, \mathrm{i}}$ \\ ${ }^{a}$ Polytechnic Institute of Portalegre, Praça do Município 11, 7300-110, Portalegre, Portugal \\ ${ }^{\mathrm{b}}$ MED- Mediterranean Institute for Agriculture, Environment and Development \& Departamento de Medicina Veterinária, Universidade de Évora, Portugal \\ ${ }^{\mathrm{c}}$ University of Ljubljana, Veterinary Faculty, Slovenia \\ ${ }^{\mathrm{d}}$ University of Utrecht, the Netherlands \\ e INRA- Institut National de la Recherche Agronomique \& Oniris, BIOEPAR Nantes, France \\ ${ }^{\mathrm{f}}$ Faculty of Veterinary Medicine, Agricultural University of Tirana, Albania \\ ${ }^{g}$ SRUC, North Faculty, Inverness, Scotland, IV2 5NA, UK \\ ${ }^{\mathrm{h}}$ Veterinary Public Health Institute, University of Bern, Switzerland \\ ${ }^{\mathrm{i}}$ Royal GD, the Netherlands
}

\section{A R T I C L E I N F O}

\section{Keywords:}

Control programmes

Non-regulated diseases

Cattle diseases

Output-based surveillance

\begin{abstract}
A B S T R A C T
Several European countries have implemented country specific programmes to control cattle diseases with little or no regulation in the European Union (EU). These control programmes vary between member states, impairing a confident comparison of freedom from disease when cattle originate from different countries. In order to facilitate safe trade, there is a need to support the development of transparent methods that enable comparison of outputs of surveillance, control or eradication programmes. The aim of the COST Action (CA 17110), Standardizing OUtput-based surveillance to control Non-regulated Diseases in the EU (SOUND control), is the development of a generic and joint understanding of the requirements and characteristics needed for a flexible output-based framework. This framework should be able to substantiate the confidence of disease freedom and cost-effectiveness of heterogeneous surveillance, control or eradication programmes for cattle diseases in the EU. This project supports other initiatives in the development of an output-based framework which will subsequently facilitate safe trade and support the improvement of disease control measures, which is of great importance as the cattle sector contributes to one third of the total gross production value of EU agriculture.
\end{abstract}

The implementation of disease control programmes (CPs) provides benefits for animals, farmers, the industry and consumers, because they increase animal health and welfare and decrease antibiotic use. Control programmes reduce direct disease losses (e.g. by decreasing the number of diseased animals and increasing production performance) and indirect disease losses (e.g. consequences of trade constraints).

The European Union (EU) has an active animal health policy and supports Member States (MS) to eradicate, control and monitor notifiable diseases. For cattle diseases that are regulated at the EU level, often input-based requirements for the disease-free status of the animal, herd and/or country are defined. Examples of input-based standards are for example the level of testing e.g. animals or herds, the matrix in which the test has to be performed e.g. blood, saliva, milk, etc. and application of defined control measures on the expectation that an adequate output will be achieved.

For cattle diseases with little or no EU regulations (termed nonregulated diseases in the remainder of this paper), country specific national or regional surveillance programmes have been implemented in many countries throughout Europe. Examples include bovine viral diarrhoea (BVD), infectious bovine rhinotracheitis (IBR), paratuberculosis, Mycoplasma bovis and salmonellosis (Memorandum of Understanding for the implementation of the COST Action, 2018). The

\footnotetext{
* Corresponding author.

E-mail address: lina_costa@ipportalegre.pt (L. Costa).
} 
heterogeneity in disease CPs and the lack of agreed upon methodologies to assess and compare health status at the herd, region and country level under such programmes, impairs the comparison of the confidence of freedom from disease of cattle between countries. Given that the different CPs are tailored to the specific country needs, it is undesirable for these diseases to move to input based standards. There is a need for the development of transparent methods that enable comparison of different CPs based on factors such as freedom from infection but also cost-effectiveness and social acceptance of these programmes (Memorandum of Understanding for the implementation of the COST Action, 2018).

Output-based standards prescribe what the surveillance must achieve in contrast to what surveillance activities must be performed as in input-based surveillance. Output-based approaches can achieve harmonized surveillance outputs that are comparable between countries. Recently, output-based approaches have been adopted internationally by the OIE and in the new EU Animal Health Law, with increased recognition of the value of risk-based sampling for demonstration of disease-free status (OIE World Organization for Animal Health, 2019; Cameron, 2012). Currently there is an EU funded study in progress that aims to develop an output-based model for comparison of freedom from BVD-infection (Roon van et al., 2019, 2020). Additionally, the merit of output-based surveillance was already studied for different infections (Cameron, 2012; Peyre et al., 2019; More et al., 2009). When correctly implemented, output-based methods can result in disease CPs tailored for each individual country based on their context risk (i.e. herd density, contact structure and disease prevalence) resulting in optimally designed, cost-effective and socially accepted CPs (OIE World Organization for Animal Health, 2019; Cameron, 2012). Consequently, output-based control has the potential to enhance the safety of animal trade, while allowing countries to decide which control measures are most suitable for their epidemiological situation (Memorandum of Understanding for the implementation of the COST Action, 2018).

A research grant was received from the European Cooperation in Science and Technology (COST, www.COST.EU) that provided the opportunity to work on the topic of output based surveillance and to achieve mutual goals with a wide variety of scientists, stakeholders, policy makers and other relevant professionals from different countries (Anon, 2020a). COST is an organization funded by the European Union Horizon 2020 framework that provides funding for researchers and innovators to set up interdisciplinary research networks.

SOUND Control - COST Action is a project of 4 years (Start date: 29/ 10/2018; End date: 28/10/2022) and at this moment only WG 1 and 2 already had results that are officially delivered and thus are ready to be presented.

In this COST Action SOUND control, more than 100 (multidisciplinary) researchers from different fields (veterinarians, epidemiologists, economists, statisticians, sociologists) from 32 countries work together to stimulate initiatives towards the development of a widely adaptable output-based framework to substantiate the confidence of freedom and cost-effectiveness in current CPs for non-EU regulated cattle diseases (Anon, 2020a).

The work in this Action was divided into five different working groups each with representatives from multiple countries. In the first Working Group (WG1) current control efforts were described for nonregulated cattle diseases within the participating countries. We started with evaluating and mapping CPs for all non-EU regulated cattle diseases (Anon, 2020b). In order to be concise, definitions for were discussed and set. First a definition of 'non-regulated' cattle disease was discussed and it was agreed that all cattle diseases not listed as A or B category disease in the upcoming new Animal Health Law (Regulation (EU) $2016 / 429,2016)$ were included in this COST Action. We further discussed classifications of disease statuses (i.e. officially free, perceived free, sporadic cases and endemic) and when a country could claim that a $\mathrm{CP}$ was in place (i.e. official documentation and implementation on regional or national level).
The first analysis of the data that was subsequently delivered by each of the participating countries reveals that among the countries included, 25 different non-EU regulated cattle diseases are controlled in one or more participating countries (Anon, 2020b). On average, there are eight CPs in place per country (minimum of 1 to maximum of 20) and the distribution per country is shown in Fig. 1. The number of CPs in place per disease are listed in Table 1 (Anon, 2020b). Note that some countries have only regional CPs in place for certain diseases. Based on this information, the next step is to obtain more detailed information about the different country specific CPs, to create a complete overview of the control efforts per disease. The most controlled diseases within the 32 countries that participate in this COST Action, "top 10 disease", are listed in Table 1 (Anon, 2020b). The preliminary results from WG1 demonstrate that most of the participating countries have a $\mathrm{CP}$ for Enzootic Bovine Leukosis, Infectious Bovine Rhinotracheitis, Bovine Viral Diarrhoea, Bluetongue, Paratuberculosis, Bovine Genital Campylobacteriosis, Anthrax and Trichomonosis. Other diseases are controlled only by a few or even by just a single country. Turkey is the country that controls the greatest number of diseases, 20. Sweden tops the list of countries that have a free status for diseases, with an official or perceived $^{1}$ free status for 13 diseases (Anon, 2020b). Another task for WG1 was to identify and reach an agreement on the scientific and practical requirements that should be met by a framework that aims at an objective comparison of the output of CPs for cattle diseases. At this stage of the project the biggest challenge is to make this framework applicable to all countries in Europe, while acknowledging the large diversity in the cattle sector structure, in risk factor occurrence and in data access and quality.

Evaluation of the availability and quality of quantitative data that is needed for an output-based framework is being conducted by Working Group 2 (WG2). First, all parameters needed to proof freedom from disease were determined for three example diseases (BVDV, BHV1, and Paratuberculosis). A data-collection tool was prepared based on previous developed tools in RISKSUR (Peyre et al., 2019) and STOC free
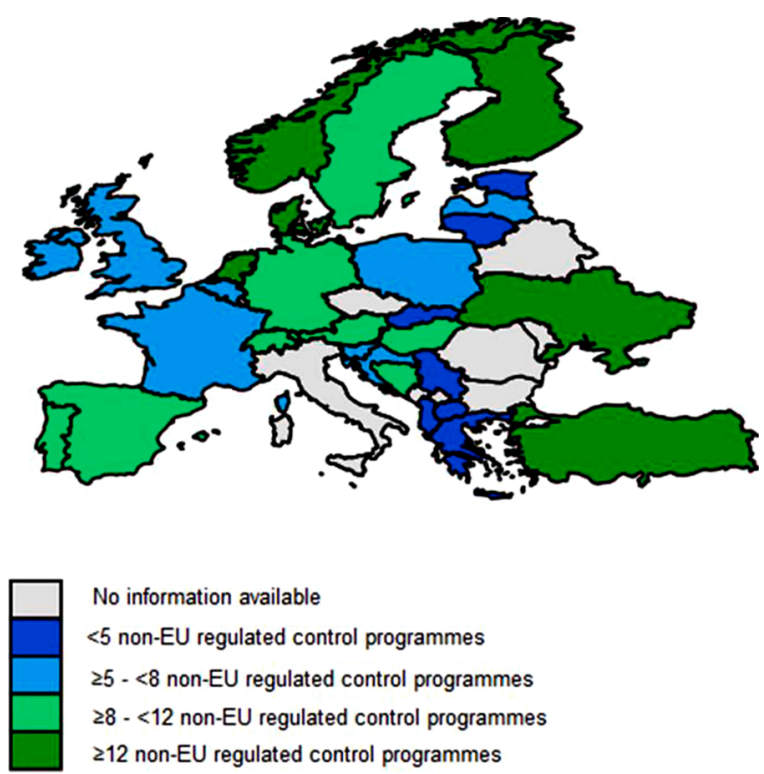

Fig. 1. Number of non-EU regulated control programmes implemented by country part of SOUND-Control COST Action.

\footnotetext{
1 The perceived free status was defined as: a country can provide evidence that there is absence from infection. There is however, no officially recognized free status by the EU.
} 
Table 1

List of cattle diseases and countries with control programmes (CPs) in place for each disease in 29 European countries that submitted information to SOUND Control in 2019.

\begin{tabular}{ll}
\hline Diseases & $\begin{array}{l}\text { Number of countries that have CPs in place for } \\
\text { the disease }\end{array}$ \\
\hline Enzootic Bovine Leukosis (EBL) & 25 \\
Bluetongue & 24 \\
Infectious Bovine Rhinotracheitis & 23 \\
$\quad$ (IBR) & \\
Bovine Viral Diarrhoea (BVD) & 22 \\
Paratuberculosis & 16 \\
Anthrax & 15 \\
Bovine Genital & 13 \\
$\quad$ Campylobacteriosis & 11 \\
Trichomonosis & 9 \\
Salmonella & 7 \\
Neosporosis & 7 \\
Epizootic Haemorrhagic Disease & 6 \\
Leptospirosis & 6 \\
Aujeszy's Disease & 5 \\
Mycoplasma bovis & 5 \\
Mycoplasma mycoides & 5 \\
Streptococcus agalactiae & 5 \\
Q-fever & 4 \\
Bovine Coronavirus & 4 \\
Staphylococcus aureus & 3 \\
Bovine Respiratory Syncytial Virus & 3 \\
Trichophyton verrucosum & 2 \\
Bovine digital dermatitis & 2 \\
Liver fluke & 2 \\
Surra &
\end{tabular}

(Roon van et al., 2019). The first draft was tested by contrasting data of two fairly different countries, Albania and the Netherlands (Table 2). The results were discussed during a workshop with the whole consortium and, based on feedback, a final version is currently under development. During the project this data-collection tool will be completed for the countries in the consortium, resulting in basic sets of input values of each of the COST countries that can be used in the output-based framework.

Working Group 3 (WG3) tasks include the evaluation of the most suitable mathematical or statistical methods for objective and standardized comparison of freedom from disease and the identification of any gaps. Within the consortium, knowledge on several statistical methods such as scenario tree modelling, Bayesian latent class models, Bayesian networks and artificial intelligence are evaluated for advantages and disadvantages in their applicability to compare CPs for freedom from disease.

Working Group 4 (WG4) is developing a research agenda to encourage researchers to solve methodological and other problems that may hinder the development, implementation, acceptance and use of output-based methods. Working Group 4 will identify mathematical, epidemiological, economic and social gaps from a variety of sources including the other WGs in the project. WG4 has adopted a participatory approach that will include surveillance and disease control experts in government and academia along with representatives from farmer and industry groups. The Working Group held a first facilitated workshop to identify information needs from output-based CPs to facilitate trade. The workshop included academic, government and industry surveillance and disease control experts. We plan to use questionnaires, in person and online workshops, and interviews with other stakeholders to explore the full range of information and other gaps that will need to be addressed before output-based CPs are accepted by all stakeholders.

The full output of this Action is communicated with the scientific community and national stakeholders by means of a specific Working Group (WG5), using several communication tools including a dedicated website (www.sound-control.eu). The knowledge that will be achieved during the SOUND control Action will be disseminated and
Table 2

A selection of data obtained for the comparison of control programs for cattle diseases in the Netherlands and Albania in 2019.

\begin{tabular}{|c|c|c|}
\hline Parameter & The Netherlands & Albania \\
\hline Cattle density & High & Low \\
\hline $\begin{array}{l}\text { Herd size (\# of } \\
\text { cattle over } 1 \mathrm{yr} \\
\text { old) }\end{array}$ & $\begin{array}{l}\text { Medium to large: average } 130 \\
\text { cows. }\end{array}$ & $\begin{array}{l}\text { Small: average } 2 \text { cows, } 73 \% \\
\text { herds less than } 5 \text { cows. }\end{array}$ \\
\hline Available data & $\begin{array}{l}\text { Many data routinely collected } \\
\text { in official census databases. }\end{array}$ & $\begin{array}{l}\text { There is an official database: } \\
\text { few parameters available. }\end{array}$ \\
\hline $\begin{array}{l}\text { Disease } \\
\quad \text { introduction } \\
\text { risk }\end{array}$ & $\begin{array}{l}\text { Many contacts between } \\
\text { herds, movement control } \\
\text { incorporated in CPs, many } \\
\text { imports. }\end{array}$ & $\begin{array}{l}\text { Many contacts between } \\
\text { herds, no strict animal } \\
\text { movement control program } \\
\text { in place. }\end{array}$ \\
\hline $\begin{array}{l}\text { Control } \\
\text { programmes in } \\
\text { place }\end{array}$ & $\begin{array}{l}\text { Many (12): some compulsory } \\
\text { (initiated by sector), some } \\
\text { voluntary }\end{array}$ & $\begin{array}{l}\text { No compulsory } \mathrm{CP}, 3 \\
\text { voluntary CPs }\end{array}$ \\
\hline $\begin{array}{l}\text { Herd biosecurity } \\
\text { level }\end{array}$ & $\begin{array}{l}\text { No representative and recent } \\
\text { data available. }\end{array}$ & $\begin{array}{l}\text { No representative and recent } \\
\text { data available }\end{array}$ \\
\hline
\end{tabular}

incorporation of an output-based framework is encouraged both at national and European level.

At the end of this project, the team will be one step closer to the development of an output-based framework that enables standardized comparison of outputs of heterogeneous disease CPs. In combination with the results of a partner project, STOC free (Roon van et al., 2019) in which an output-based framework to determine freedom from disease is being developed, the fundamentals are laid to move towards increased application of output-based systems. Although the primary focus of this Action concerns non-harmonized disease CPs, outcomes of this project will also be applicable for EU regulated diseases, which are currently mostly sustained by input-based standards. The developed framework should be adaptable not only to multiple diseases but also to different animal species. Projects such as SOUND control aim to move towards a single general regulatory output-based framework that is applicable for comparison of freedom from disease, is cost-effective and is socially acceptable among different countries.

\section{Funding}

This work is supported by Horizon 2020 Framework Programme of the European Union and COST - European Cooperation in Science \& Technology.

\section{Declaration of Competing Interest}

The authors report no declarations of interest.

\section{References}

Anon, 2020a. SOUND-CONTROL Cost Action Website (Accessed 6 August 2020). https: //sound-control.eu/.

Anon, 2020b. Overview of Non-Regulated Cattle Diseases in the European Union for which Control Programmes (CPs) Are in Place within Member States (MS) May. https://sound-control.eu/reports-publications/.

Cameron, A.R., 2012. The consequences of risk-based surveillance: developing output based standards for surveillance to demonstrate freedom from disease. Prev. Vet. Med. 105, 208-286.

Memorandum of Understanding for the implementation of the COST Action, 2018. Standardizing Output-Based Surveillance to Control Non-regulated Diseases of Cattle in the EU (SOUND-control) CA17110. Brussels, 13 April 2018. Available at. https:// sound-control.eu/reports-publications/.

More, S.J., Cameron, A.R., Greiner, M., Clifton-Hadley, R.S., Correia Rodeia, S. Bakker, D., Salman, M.D., Sharp, J.M., De Massis, F., Aranaz, A., Boniorri, M.B., Gaffuri, A., Have, P., Verloo, D., Woodford, M., Wierup, M., 2009. Defining outputbased standards to achieve freedom and maintain tuberculosis freedom in farmed deer, with reference to member states of the European Union. Prev. Vet. Med. 90, 254-267.

OIE World Organization for Animal Health, 2019. Animal health surveillance. Terrestrial Animal Health Code. Available at Chapter 1.4. https://www.oie.int/index.php?id $=169 \& \mathrm{~L}=0 \& \mathrm{htm}$ file $=$ chapitre surveillance general.htm.

Peyre, M., Hoinville, L., Njoroge, J., Cameron, Al, Traon, D., Goutard, F., Calba, C., Grosbois, V., Delabouglise, A., Varant, V., Drewe, J., Pfeiffer, D., Häsler, B., 2019. 
The RISKSUR EVA tool (Survtool): a tool for the integrated evaluation of animal health surveillance systems. Prev. Vet. Med. 173 https://doi.org/10.1016/j. prevetmed.2019.104777.

Regulation (EU) 2016/429, 2016. On Transmissible Animal Diseases and Amending and Repealing Certain Acts in the Area of Animal Health ('Animal Health Law')

(Accessed 6 August 2020). https://eur-lex.europa.eu/legal-content/EN/TXT/? uri=OJ:L:2016:084:TOC.

Roon van, A.M., Santman-Berends, I.M.G.A., Graham, D., More, S.J., Nielen, M.,

Madouasse, A., Mercat, M., Fourichon, C., Gethmann, J., Frössling, J., Lindberg, A. Correira-Gomes, C., Gunn, G.J., Sauter-Louis, C., Henry, M.K., Duijn van, L., Schaik van, G., 2019. An innovative framework to compare probability of freedom from infection in heterogeneous control programmes. Front. Vet. Sci. 6, 133. https://doi. org/10.3389/fvets.2019.00133.

Roon van, A.M., Santman-Berends, I.M.G.A., Graham, D., More, S.J., Nielen Duijn van, L., Mercat, M., Fourichon, C., Madouasse, A., Gethmann, J., Sauter-Louis, C., Frössling, J., Lindberg, A., Correira-Gomes, C., Gunn, G.J., Henry, M.K., Schaik van, G., 2020. A qualitative comparison of factors influencing confidence of freedom from bovine viral diarrhoea virus infection in six European control programs.

J. Dairy Sci. Accepted for publication. 